\title{
OS DIREITOS DA PERSONALIDADE EM FACE DA DICOTOMIA DIREITO PÚBLICO - DIREITO PRIVADO
}

\author{
THE RIGHTS OF PERSONALITY IN THE FACE OF DICOTOMY PUBLIC LAW AND \\ PRIVATE LAW
}

Leonardo Estevam de Assis Zanini

Livre-docente em Direito Civil pela USP (2017). Pós-doutor em Direito Civil pelo MaxPlanck-Institut für ausländisches und internationales Privatrecht (Alemanha). Pós-

doutorado em Direito Penal pelo Max-Planck-Institut für ausländisches und internationales Strafrecht (Alemanha). Doutor em Direito Civil pela USP (2013), com estágio de doutorado na Albert-Ludwigs-Universität Freiburg (Alemanha). Mestre em Direito Civil pela PUC-SP (2010). Bacharel em Direito pela USP (2000). Juiz Federal. Professor Universitário. Pesquisador do grupo Direito e Desenvolvimento Público da Universidade de Araraquara (UNIARA). Pesquisador do grupo Novos Direitos CNPq/UFSCar. E-mail: lezanini@trf3.jus.br

Edmundo Alves de Oliveira

Doutor em Sociologia pela UNESP. Professor de Sociologia Geral e Jurídica da Universidade de Araraquara - Uniara. Assistente da Coordenação do Curso de Direito do

Centro Universitário de Araraquara. Realiza pesquisa na área de sociologia jurídica, política e administração com financiamento da agencia de fomento FUNADESP Fundação Nacional de Desenvolvimento do Ensino Superior Particular, líder do grupo de pesquisa Direito e Desenvolvimento Público da Universidade de Araraquara (UNIARA).

E-mail:edmundoedmundo@gmail.com

\section{Dirceu Pereira Siqueira}

- Pós-doutor em Direito pela Universidade de Coimbra, Doutor e Mestre ITE/Bauru. Pesquisador Bolsista - Modalidade Produtividade em Pesquisa para Doutor - PPD - do Instituto Cesumar de Ciência, Tecnologia e Inovação (ICETI). Professor da Universidade de Araraquara - Uniara. Professor Permanente do Programa de Mestrado em Direito do

Centro Universitário Unicesumar. Professor Convidado do Programa de Mestrado em "Gestão Estratégica de Empresas" - Master Of Science in Administrative Studies (MSAS) - University Missouri State - EUA. Líder do grupo de pesquisa Direito e Desenvolvimento Privado da Universidade de Araraquara. E-mail: dpsiqueira@uol.com.br

\section{Raul de Mello Franco Jr.}

Doutor em Ciências Jurídico-Políticas pela Faculdade de Direito da Universidade de Lisboa (Portugal), Mestre em Direito Público pela UNESP - Universidade Estadual

Paulista Júlio de Mesquita Filho, Professor de Direito Constitucional da UNIARA Universidade de Araraquara e Promotor de Justiça - membro do Ministério Público do

Estado de São Paulo. Pesquisador do grupo Direito e Desenvolvimento Público da Universidade de Araraquara (UNIARA) - E-mail: raulmfranco@gmail.com

Recebido em:18/04/2017

Aprovado em: 22/08/2017 
RESUMO: O presente estudo busca analisar a clássica divisão do direito em público e privado, o que é feito a partir de uma metodologia fundamentalmente bibliográfica. Partindo da distinção entre direito público e privado procura-se posicionar a situação dos direitos da personalidade, bem como a efetivação destes direitos em favor de pessoas e grupos de pessoas. As implicações e distinções são relevantes e poderão facilitar o entendimento dos avanços ou retrocessos da matéria. Indaga-se ainda se a distinção, que remonta ao direito romano, ainda tem relevância e se é válida na atualidade.

Palavras-chave: Direitos da personalidade; Efetivação; Direito público; Direito privado.

ABSTRACT : The present study seeks to analyze, through a bibliographical methodology, the rights of the personality in the contemporary perspective, starting from the distinction between public and private law in order to establish the verification of the different but necessary ways of effecting these rights in favor of individuals and groups of people. The implications and distinctions are relevant and may represent advances or setbacks to the realization of these rights, hence the need for a better understanding. The reflexes of the present analysis are very relevant for the legal area, since they reinforce favorable arguments for the constant implementation of measures that can effect the rights of the personality, a scenario in which the state has an important role of primary actor. Therefore, to place properly, the quadrant and the rules to be applied in favor of the realization of the rights of the personality are of great importance for the society.

Keywords: Personality rights; Effectiveness; Public Right; Private right.

SUMÁRIO: Introdução; 1. A dicotomia entre o Direito Público e o Direito Privado; 2. Os fundamentos da Dicotomia entre o Direito Público e o Direito Privado; 3. Direito Público e Direito Privado: Uma distinção em crise?; 4. A situação dos Direitos da Personalidade; Conclusão; Referências Bibliograficas.

\section{INTRODUÇÃO}

O artigo propõe uma reflexão sobre a dicotomia entre do direto público e privado que pode ser percebida desde o direto romano. Sua fórmula pode ser extraída da seguinte sentença de Ulpiano: "Hujus studii duae sunt positiones, publicum et privatum. Publicum jus est quod ad statum rei romanae spectat, privatum, quod ad singulorum utilitatem" (Digesto, 1.1.1.2). Assim, entre os romanos o direito público era aquele que dizia respeito ao estado dos negócios romanos, enquanto que o direito privado disciplinava os interesses particulares ${ }^{1}$.

Esta breve incursão no pensamento romano permite aquilatar a considerável diferença dos diques que hoje constituem as fronteiras do público e do privado. A separação ganha nova relevância na era moderna quando é, com enfoque diverso, caracterizado pela oposição entre dois conjuntos (a sociedade e o indivíduo). Neste contexto desponta um novo elemento distintivo e artificial: o Estado. ${ }^{2}$ Estado e suas distintas configurações ao longo do tempo tem permitido mais ou menos nitidez no que se refere a distinção entre direito público e privado.

Esta distinção entre direito público e privado estabelece as formas de efetivação destes direitos em favor de pessoas e grupos de pessoas na realidade imposta pelo século XXI. Desta forma, o objetivo central do artigo, assentado nos fundamentos do direito romano e nas diferentes configurações históricas que assumiram a distinção entre direito público e privado, é estabelecer uma base de entendimento do direito a personalidade na atualidade.

\footnotetext{
${ }^{1}$ DINIZ, Maria Helena. Compêndio de Introdução à Ciência do Direito. 19. ed. São Paulo: Saraiva, 2008, p. 250251.

${ }_{2}^{2}$ FERRAZ JUNIOR, Tercio Sampaio, Introdução ao estudo de direito: técnica, decisão, dominação, p. 136-137. Revista de Direito Brasileira | São Paulo, SP | v. 19 | n. 8 | p. 208 - 220 |Jan./Abr. 2018
} 


\section{A DICOTOMIA ENTRE O DIREITO PÚBLICO E O DIREITO PRIVADO}

Tercio Sampaio Ferraz Junior, com base nos ensinamentos de Hannah Arendt, pontifica que essa separação entre a esfera pública e a privada caracterizava a cultura da Antiguidade de uma forma assaz peculiar. Para os antigos, a esfera privada compreenderia o reino da necessidade, o qual obrigaria o homem, se quisesse sobreviver, a exercer o labor, que estava ligado ao processo ininterrupto de produção de bens de consumo, como, por exemplo, os alimentos. Esses produtos não tinham permanência no mundo, já que eram bens perecíveis, e ainda exigiam, para a sua elaboração, instrumentos que se confundiam com o próprio corpo (os braços, as mãos, bem como suas extensões). A sede do labor era a casa (domus, oikia), locus das relações familiares baseadas nas diferenças, eis que o comando da casa era do pater familias, senhor de sua mulher, de seus filhos e de seus escravos. É neste ponto que encontramos a esfera privada, ou seja, no "âmbito em que o homem, submetido às necessidades da natureza, buscava sua utilidade no sentido de meios de sobrevivência". ${ }^{3}$

Por outro lado, os cidadãos empreendiam sua atividade em outro âmbito, ou seja, na cidade (polis), onde se encontravam entre os iguais. A atividade por eles exercida era a ação, a qual se assemelhava ao labor, pela permanente continuidade. A dessemelhança se encontrava no fato de que a ação dignificava o homem, conferindo-lhe liberdade, já que seu terreno era o do encontro dos cidadãos livres que se governavam. Daí que a ideia de ação política era "dominada pela palavra, pelo discurso, pela busca dos critérios do bem governar, das normas do direito. A vida política constituía a esfera pública. Sendo, das atividades, a mais característica do ser humano, a ação permitiu a ideia do animal político".

Quando Ulpiano distinguiu o direito público do direito privado, na verdade considerava como esfera pública o lugar da ação, da interrelação dos homens livres; tomava como esfera privada o local do labor, isto é, a casa e as atividades vocacionadas à sobrevivência ${ }^{5}$.

Essa distinção, porém, tão cara ao direito romano, perdeu seu sentido na Idade Média. ${ }^{6}$ É que nesse período, conforme obtempera Marcos de Campos Ludwig, a ausência de um poder político centralizado tornou a dicotomia um "impossível histórico". Imperavam no direito "[...] as marcas de status e suas respectivas relações hierarquizadas, com forte influência do costume e da Igreja enquanto pilar último da organização social do feudalismo". ${ }^{7}$ Quase tudo se confundia com a propriedade do suserano ou da Igreja, o que negava espaço para a divisão entre o público e o privado.

O direito explicado pelo poder soberano, tomado pelo comando, daria vida à esfera pública, em oposição à esfera privada que, apesar de também ser social, carecia desses atributos, eis que ligada ao poder dos indivíduos nas suas relações. ${ }^{8}$

Ademais, a summa divisio entre direito privado e o direito público também encontrava força na luta pela redução dos abusos do absolutismo, visto que se buscou "delimitar ao máximo os espaços de intervenção do Estado e os espaços de atuação privada. A divisão entre esses dois ramos era fundamental para a organização do direito, do Estado e da sociedade". 9

Outro não foi o sentido do movimento codificatório, cujo marco exponencial foi o Código Civil francês. Valendo-se das codificações, a burguesia pretendia determinar, de forma

\footnotetext{
${ }^{3}$ FERRAZ JUNIOR, Tercio Sampaio. Introdução ao estudo de direito: técnica, decisão, dominação. 2. ed. São Paulo: Atlas, 1994, p. 134.

${ }^{4}$ FERRAZ JUNIOR, Tercio Sampaio, Introdução ao estudo de direito: técnica, decisão, dominação, p. 135.

${ }^{5}$ Cf. FERRAZ JUNIOR, Tercio Sampaio, Introdução ao estudo de direito: técnica, decisão, dominação, p. 135.

${ }^{6}$ BORGES, Roxana Cardoso Brasileiro, Direitos de personalidade e autonomia privada, p. 78.

${ }^{7}$ LUDWIG, Marcos de Campos. Direito público e privado: a superação da dicotomia. In: MARTINS-COSTA, Judith. A reconstrução do direito privado: reflexos dos princípios, diretrizes e direitos fundamentais constitucionais no direito privado. São Paulo: Revista dos Tribunais, 2002, p. 95.

${ }^{8}$ FERRAZ JUNIOR, Tercio Sampaio, Introdução ao estudo de direito: técnica, decisão, dominação, p. 136-137.

${ }^{9}$ BORGES, Roxana Cardoso Brasileiro, Direitos de personalidade e autonomia privada, p. 74. 
bem clara, o âmbito das relações privadas, de modo a assegurar a não intervenção do Estado nessa seara e limitá-lo aos escaninhos do direito público. ${ }^{10}$

As codificações tiveram papel determinante no traçado das fronteiras entre as esferas pública e privada. O Estado foi praticamente alijado das relações entre particulares, o que representou severa redução do espaço relacional entre as duas esferas do ordenamento jurídico, tornando estanques os ambientes da proteção da pessoa. ${ }^{11}$

Ao lado do movimento das codificações, não se pode esquecer do constitucionalismo, que deu vida às liberdades negativas e delimitou nitidamente o espaço de atuação do Estado na moldura dos direitos individuais. ${ }^{12}$

Em síntese, o reinado do liberalismo clássico, os movimentos de codificação e o constitucionalismo tornaram singelas e de fácil percepção, no século XIX, as diferenciações entre as esferas pública e privada.

A distinção objetiva, porém, perdeu sensivelmente sua nitidez com o surgimento do Estado de Bem-Estar Social (Welfare State), que abandonou a doutrina liberal, acolheu as chamadas liberdades positivas e inaugurou novas frentes do direito, como o direito do consumidor, o direito ambiental, o direito do trabalho etc. ${ }^{13}$, herdeiros de contribuições tanto do manancial jurídico público como privado.

Com isso, a esfera pública e a esfera privada ganham espaços de intersecção, sobrepondo-se em áreas que dificultam a identificação de suas fronteiras, desafiando novas concepções doutrinárias ou incentivando, em outro extremo, teorias que negam a prevalência da dicotomia.

De qualquer forma, é interessante notar que a divisão entre público e privado é traço característico dos direitos da família romano-germânica, não existindo essa preocupação em outras famílias jurídicas, como no direito inglês e no direito dos países do hemisfério oriental ${ }^{14}$.

Passaremos agora ao estudo das teorias que procuram justificar a separação dessas esferas e, em seguida, à questão da necessidade ou não de sua manutenção no direito, bem como do espaço ocupado pelos direitos da personalidade.

\section{OS FUNDAMENTOS DA DICOTOMIA ENTRE O DIREITO PÚBLICO E O DIREITO PRIVADO}

Diversas teorias foram desenvolvidas na tentativa de pontuar a distinção entre o direito público e o direito privado, o que não constitui novidade, haja vista que os romanos já palmilhavam dificuldades nesse campo. Merecem destaque as teorias do sujeito, do interesse e da relação de dominação.

A teoria do sujeito (ou teoria da natureza da situação jurídica, como prefere Rosa Maria de Andrade Nery ${ }^{15}$ ) procura distinguir o direito público do direito privado a partir do destinatário das normas. O primeiro teria o Estado por destinatário, enquanto o último voltar-se-ia aos particulares. O problema dessa doutrina está no fato de que muitas vezes o Estado ou as pessoas a ele equiparadas têm atuação que não difere daquela dos particulares, o que acaba restringindo o

\footnotetext{
${ }^{10}$ BORGES, Roxana Cardoso Brasileiro, Direitos de personalidade e autonomia privada, p. 77.

${ }^{11}$ DONEDA, Danilo. Os direitos da personalidade no novo Código Civil. In: TEPEDINO, Gustavo (org.). A parte geral do novo Código Civil. 3. ed. Rio de Janeiro: Renovar, 2007, p. 39.

${ }^{12}$ LUDWIG, Marcos de Campos. Direito público e privado: a superação da dicotomia. In: MARTINS-COSTA, Judith. A reconstrução do direito privado: reflexos dos princípios, diretrizes e direitos fundamentais constitucionais no direito privado. São Paulo: Revista dos Tribunais, 2002, p. 96-97.

${ }^{13}$ BORGES, Roxana Cardoso Brasileiro, Direitos de personalidade e autonomia privada, p. 74.

${ }^{14}$ LUDWIG, Marcos de Campos. Direito público e privado: a superação da dicotomia. In: MARTINS-COSTA, Judith. A reconstrução do direito privado: reflexos dos princípios, diretrizes e direitos fundamentais constitucionais no direito privado. São Paulo: Revista dos Tribunais, 2002, p. 87-88.

${ }^{15}$ NERY, Rosa Maria de Andrade, Introdução ao pensamento jurídico e à teoria geral do Direito Privado, p. 172.
}

Revista de Direito Brasileira | São Paulo, SP | v. 19 | n. 8 | p. 208 - 220 |Jan./Abr. 2018 
seu âmbito de validade ${ }^{16}$. Vale como exemplo a compra em que seja dispensada a licitação em razão do pequeno valor do bem a ser adquirido (Lei 8.666/93).

A teoria do interesse opõe a sociedade ao indivíduo, cada um com seus próprios núcleos de atenção e vantagens. Para essa teoria, que se difundiu no século XIX graças ao trabalho da Escola da Jurisprudência dos Interesses e de Rudolf von Ihering, os interesses da sociedade, representados pelo Estado, seriam comuns, "neutros em face dos egoísmos particulares", envolvendo a gestão da coisa pública e da economia nacional. Todavia, esse critério perde força com a eclosão de interesses que se situam entre o público e o privado, como é o caso dos direitos trabalhistas. $^{17}$

Com efeito, muitas vezes não é possível uma afirmação categórica acerca da essência do interesse protegido, ou seja, embaraçam-se os elementos que permitem qualificá-lo como do Estado ou dos indivíduos, vez que "nenhuma norma atinge apenas o interesse do Estado ou o do particular. Há uma correlação, de modo que a norma jurídica que tiver por finalidade a utilidade do indivíduo visa também à do Estado e vice-versa". ${ }^{18}$

A crítica levou alguns autores então a fundamentar a distinção no interesse preponderante, pelo que as normas de direito público garantiriam diretamente o interesse da sociedade e indiretamente o do particular, ocorrendo exatamente o contrário com as normas de direito privado. Todavia, segundo Maria Helena Diniz, esse critério também é insatisfatório, dado que os interesses estão tão interligados "que é impossível verificar, com exatidão, qual o que prepondera". 19

Finalmente, há a teoria da relação de dominação (ou teoria da posição do sujeito da situação jurídica, conforme Rosa Maria de Andrade $\mathrm{Nery}^{20}$ ), que considera nas relações do direito público a atuação do Estado com poderes de autoridade (ius imperii), pondo-se superiormente aos entes privados. Estes, por outro lado, mantém entre si relações de paridade, sem a presença do ius imperii. Com isso, destaca-se nas relações sociais o monopólio da força pelo Estado, o que é feito graças à concentração e centralização do poder de impor condutas, sendo que a unidade do Poder Público, para essa concepção, estaria fulcrada na noção de soberania $^{21}$.

Essa teoria, por sua vez, não passa imune às críticas de Brox e Walker que, em um primeiro momento, apresentam o direito privado (Privatrecht) como a parte do direito que regula as relações entre participantes da sociedade que se põem em relação de paridade, enquanto que o direito público (öffentliches Recht) cuidaria da regulação das relações em que não haveria tal paridade. Em seguida, os autores tedescos ponderam que essa delimitação nem sempre é admitida. Há situações no direito privado em que os protagonistas da relação jurídica se colocam em situação díspar, como é o caso das relações entre os pais e os filhos. Lembram, ainda, que no direito público também despontam situações de paridade, como aquelas que se dão nas relações entre duas municipalidades ${ }^{22}$. E Maria Helena Diniz acrescenta que "mesmo os sujeitos dotados de imperium podem ser sujeitos de direito privado, como na hipótese em que o Estado é parte num contrato de compra e venda ou num contrato de locação". ${ }^{2}$

Rosa Maria de Andrade Nery observa que os critérios apresentados pelas teorias indubitavelmente correspondem a aspectos possíveis de serem invocados na distinção das

\footnotetext{
${ }^{16}$ FERRAZ JUNIOR, Tercio Sampaio, Introdução ao estudo de direito: técnica, decisão, dominação, p. 139.

${ }^{17}$ FERRAZ JUNIOR, Tercio Sampaio, Introdução ao estudo de direito: técnica, decisão, dominação, p. 139.

${ }^{18}$ DINIZ, Maria Helena, Compêndio de Introdução à Ciência do Direito, p. 251.

${ }^{19}$ DINIZ, Maria Helena, Compêndio de Introdução à Ciência do Direito, p. 252.

${ }^{20}$ NERY, Rosa Maria de Andrade, Introdução ao pensamento jurídico e à teoria geral do Direito Privado, p. 172.

${ }^{21}$ FERRAZ JUNIOR, Tercio Sampaio, Introdução ao estudo de direito: técnica, decisão, dominação, p. 140.

${ }^{22}$ BROX, Hans; WALKER, Wolf-Dietrich, Allgemeiner Teil des BGB, p. 10.

${ }^{23}$ DINIZ, Maria Helena, Compêndio de Introdução à Ciência do Direito, p. 253.
} 
categorias. Contudo, não bastam para o perfeito esclarecimento das discrepâncias existentes entre elas. $^{24}$

A mesma insuficiência leva Maria Helena Diniz a apontar os defensores de uma teoria eclética, que associa os elementos objetivo e subjetivo. O direito público seria aquele que regularia as relações em que o Estado é parte, atuando em razão de seu poder soberano e objetivando a tutela do bem coletivo; o direito privado disciplinaria "as relações entre particulares, nas quais predomina, de modo imediato, o interesse de ordem privada, como compra e venda, doação, usufruto, casamento, testamento, empréstimo etc". ${ }^{25}$ Mas é inegável que essa noção não passa de uma aglutinação das ideias já desenvolvidas pela doutrina, o que leva a jurista a reconhecer, em nome da unidade do direito, a inexistência de uma solução absoluta ou perfeita para o problema da distinção entre o direito público e o direito privado:

Embora o direito objetivo constitua uma unidade, sua divisão em público e privado é aceita por ser útil e necessária, não só sob o prisma da ciência do direito, mas também sob o ponto de vista didático. Todavia, não se deve pensar que sejam dois compartimentos estanques, estabelecendo uma absoluta separação entre as normas de direito público e as de direito privado, pois intercomunicam-se com certa frequência. ${ }^{26}$

Pode-se concluir, assim, que não obstante os esforços envidados pela juspublicística, a maioria da doutrina segue admitindo que não há uma concepção que consiga distinguir cabalmente o direito público do direito privado ${ }^{27}$. A rigor, não se trata de novidade. Há milênios o direito tem trabalhado com essas categorias sem, contudo, encontrar teoria que pudesse dogmatizá-las em espaços estanques e incomunicáveis.

Soma-se a isso o fato de que a sociedade e o direito, particularmente no pós-guerra, ganharam novas nuances, matizes que recolocaram em cena a milenar distinção, profligada por doutrinadores, muitos dos quais passaram a advogar a tese da sua superação. É o ponto que se pretende abordar na sequência.

\section{DIREITO PÚBLICO E DIREITO PRIVADO: UMA DISTINÇÃO EM CRISE?}

As transformações revolucionárias pelas quais vêm passando o direito (particularmente o direito civil), atingido, entre outros, pelos movimentos da constitucionalização, da personalização, da descentralização e da recodificação, têm tornado cada vez mais difícil o delineamento das fronteiras entre o direito público e o direito privado.

Fala-se, na atualidade, na privatização do direito público e na publicização do direito privado, uma vez que técnicas e institutos tradicionalmente reconhecidos como pertencentes ao direito privado são empregadas no direito público e vice-versa. Autores de escol, como Perlingieri, afirmam que a distinção, em tal contexto, "não é mais qualitativa, mas quantitativa". ${ }^{2}$

Parece notório que é cada vez mais difícil apontar um interesse particular que se apresente, de forma extreme, independente do interesse público. Até mesmo o direito de propriedade, cultuado pelos doutrinadores oitocentistas como absoluto, hoje se vê bastante limitada por normas que reformaram sua essência e funcionalidade (e.g. art. 182, §2 ${ }^{\circ}$ da CF e art. $1.228, \S \S 1^{\circ}$ e $2^{\circ}$ do Código Civil).

Com isso, não há mais espaço para a vetusta ideia de um direito privado que se assente na liberdade concedida a cada um para cuidar, até mesmo arbitrariamente, dos próprios

\footnotetext{
${ }^{24}$ NERY, Rosa Maria de Andrade, Introdução ao pensamento jurídico e à teoria geral do Direito Privado, p. 174.

${ }^{25}$ DINIZ, Maria Helena, Compêndio de Introdução à Ciência do Direito, p. 255.

${ }^{26}$ DINIZ, Maria Helena, Compêndio de Introdução à Ciência do Direito, p. 256.

${ }^{27}$ FERRAZ JUNIOR, Tercio Sampaio, Introdução ao estudo de direito: técnica, decisão, dominação, p. 140.

${ }^{28}$ PERLINGIERI, Pietro, Perfis do direito civil, p. 54.
}

Revista de Direito Brasileira | São Paulo, SP | v. 19 | n. 8 | p. 208 - 220 |Jan./Abr. 2018 
interesses. Por outro lado, tampouco o direito público tutela apenas a soberania e a estruturação do Estado, estendendo suas preocupações a interesses até então tidos como meramente privados. $^{29}$

Há, outrossim, talvez como complicador da distinção, o aumento dos interesses que se alojam em categoria intermediária, como, por exemplo, o sindical ou das comunidades ${ }^{30}$.

Natural que, neste cenário, ganhem adeptos as escolas que rezam o réquiem da distinção entre o direito público e o direito privado ou somente assentem a dicotomia a partir de critérios de preponderância. Pietro Perlingieri e Pasquale Femia, por exemplo, reconhecem a dificuldade da distinção, a menos que se acolha um critério quantitativo, visto que em todos os setores do direito convivem normas públicas e privadas, prevalecendo às vezes o aspecto privatístico, quando se satisfaz diretamente um interesse singular e, em outros casos, o aspecto publicístico. ${ }^{31}$

Partindo daí, acolhem os autores italianos uma distinção bastante peculiar, pois reconhecem a inadequação da expressão "direito privado", substituindo-a por direito civil, que entendem como aquele direito em condições de igualdade, o direito de todos, que não está em antítese com o direito público, mas sim que parte de um ordenamento unitário e que constitui somente um ramo que se justifica por razões didáticas e de especialização profissional ${ }^{32}$.

Entretanto, mesmo antes dessa grande polemização, já se reconhecia que o direito deve ser visto como um todo dotado de coerência, o que, porém, não significa que o sistema jurídico seja um conjunto rigorosamente lógico. ${ }^{33}$

Ora, o que se está vendo nos últimos tempos é justamente o reflexo da unidade do direito, que sempre existiu e, anteriormente, somente era mais perceptível em determinadas áreas da ciência jurídica, como é o caso do direito de família, em que a tutela estatal era constante, mas que nem por isso passou a ser considerado como direito público.

De forma semelhante, professa Perlingieri:

O fracionamento da matéria jurídica e do ordenamento em ramos tem um sentido porque divide por competências e por necessidade de exposição uma matéria única em si mesma, mas não deve significar que a realidade do ordenamento é divisível em diversos setores dos quais um é totalmente autônomo em relação ao outro, de tal modo que possa ser proclamada a sua independência. ${ }^{34}$

Neste prisma, a divisão do direito em público e privado tem utilidade prática e didática, mesmo porque, se não pudermos admiti-la, também não poderíamos pretender a distinção, ainda de maior especialização, entre os vários ramos do direito e que não deixa de partir das mesmas raízes público-privadas.

Ao contrário, vê-se, paulatinamente, um número cada vez maior de áreas do direito pretendendo sua independência (e.g. direito agrário, aeronáutico, do autor, marítimo etc.), o que é visto com naturalidade pelos mesmos autores que advogam a superação da distinção entre o direito público e o direito privado.

De qualquer forma, mesmo sendo incontestável a intersecção entre os ramos do direito, acreditamos que, pelo menos sob a ótica até então existente, mantêm-se vivas as esferas individual e pública, nada obstante o aparecimento de categorias que poderiam ser consideradas

\footnotetext{
${ }^{29}$ PERLINGIERI, Pietro, Perfis do direito civil, p. 55-56.

${ }^{30}$ PERLINGIERI, Pietro, Perfis do direito civil, p. 53.

${ }^{31}$ PERLINGIERI, Pietro; FEMIA, Pasquale. Nozioni introduttive e principi fondamentali del diritto civile. Napoli: Edizioni Scientifiche Italiane, 2004, p. 70.

${ }^{32}$ PERLINGIERI, Pietro; FEMIA, Pasquale, Nozioni introduttive e principi fondamentali del diritto civile, p. 71.

${ }^{33}$ FERRAZ JUNIOR, Tercio Sampaio, Introdução ao estudo de direito: técnica, decisão, dominação, p. 141.

${ }^{34}$ PERLINGIERI, Pietro, Perfis do direito civil, p. 55.
}

Revista de Direito Brasileira | São Paulo, SP | v. 19 | n. 8 | p. 208 - 220 |Jan./Abr. 2018 
intermediárias, híbridas, o que, igualmente, garante a validade da separação dos campos do direito em público e privado.

Aliás, a vitalidade da separação entre as esferas pública e privada pôde ser muito bem constatada quando entrou em vigor a Lei 9.434, de 04 de fevereiro de 1997. Tal lei, na tentativa afobada de aumentar o número de transplantes, defendendo, portanto, o interesse público, estabeleceu a presunção de que todo brasileiro autorizava a doação de tecidos, órgãos ou partes do corpo humano para finalidade de transplantes ou terapêutica. Para isso, dispôs em seu que caso assim não desejasse, o cidadão deveria gravar a expressão "não-doador de órgãos e tecidos" em seu documento de identidade (cf. art. $3^{\circ}, \S 3^{\circ}$ ), o que certamente violava a sua intimidade, eis que o documento seria visualizado por um número indeterminado de pessoas.

A oposição social generalizada obrigou a revogação da presunção e da inscrição no documento pessoal (lei $10.211 / 2001)^{35}$, a demonstrar a ainda atual e nítida separação entre as esferas pública e privada, visto que a sociedade brasileira tem consciência dessas esferas e não admite a invasão desproporcional de uma delas na outra.

Celeumas semelhantes, sempre a questionar a excessiva e indevida intromissão da regulação pública na esfera privada, foram suscitadas pela chamada "lei das palmadas" (lei 13.010/2014, que promovendo alterações no Estatuto da Criança e do Adolescente (ECA), imiscui-se na educação familiar) e pela "lei do cigarro" (lei 9.294/1996 - proibindo o uso de cigarros, cigarrilhas, charutos e assemelhados inclusive em recintos coletivos, ainda que privados).

Outrossim, parece-nos que em relação à didática e à prática a distinção se faz certamente necessária, pois organiza as normas e as condutas levando em consideração os distintos objetivos, fundamentos e princípios. ${ }^{36}$

Não é outro o entendimento de Tercio Sampaio Ferraz Junior, que salienta que apesar das críticas, particularmente no que toca à falta de rigor, a dicotomia ainda persevera, dada a sua operacionalidade pragmática e seu enraizamento em quase todo o mundo, servindo ao jurista "como instrumento sistematizador do universo normativo para efeitos de decidibilidade". 37

É mesmo difícil de se conceber, nos países de tradição romano-germânica, o ensino jurídico apartado da distinção entre o direito público e o direito privado. A dicotomia também foi levada em consideração pelo constituinte brasileiro, que em nossa Carta Magna reconhece a existência de vários setores do direito (e.g. direito civil, comercial, penal, processual, tributário, do trabalho, eleitoral, agrário, marítimo, aeronáutico, espacial, financeiro, econômico), bem como arrola princípios que regem alguns desses ramos jurídicos, o que reforça a sua manutenção, mesmo porque um dos critérios utilizados para a classificação está justamente nos princípios que regem o direito público e o direito privado.

A manutenção da dicotomia, porém, não significa que direito público e direito privado devam ser encarados tal qual os viam os juristas do século XIX. Não quer dizer que estamos admitindo a separação do direito em compartimentos estanques, como pretendiam os autores liberais e cientificistas.

Em realidade, vivemos nos dias atuais uma suavização das dessemelhanças, bem como do aumento da complementaridade das esferas, dada a unidade do ordenamento jurídico, o que não nos impede de reconhecer que os ramos do direito são "compostos por normas com algumas características mais fortes de direito público ou de direito privado, com objetivos e princípios específicos". ${ }^{38}$

\footnotetext{
${ }^{35}$ AZEVEDO, Álvaro Villaça; NICOLAU, Gustavo Rene. Código civil comentado: das pessoas e dos bens: artigos $1^{\circ}$ a 103. AZEVEDO, Álvaro Villaça (coord.). São Paulo: Atlas, 2007, v. I, p. 57-58.

${ }^{36}$ BORGES, Roxana Cardoso Brasileiro, Direitos de personalidade e autonomia privada, p. 94.

${ }^{37}$ FERRAZ JUNIOR, Tercio Sampaio, Introdução ao estudo de direito: técnica, decisão, dominação, p. 138.

${ }^{38}$ BORGES, Roxana Cardoso Brasileiro, Direitos de personalidade e autonomia privada, p. 90.
} 
A constitucionalização e a funcionalização do direito privado sem dúvida contribuem para o seu distanciamento da concepção tradicional, ensinada até tão pouco tempo nos bancos das faculdades de direito do Brasil e que preconizava o dogma absoluto da livre vontade dos sujeitos. Um direito privado que tencionava "prevenir ingerência nas esferas dos particulares e a intromissão arbitrária da autoridade na liberdade das pessoas"39.

Em conformidade com essa nova realidade jurídica, adverte Rosa Maria de Andrade Nery que para a delimitação do âmbito de cada um dos termos da presente dicotomia é necessária a análise da finalidade imediata, isto é:

Se estivermos diante do exercício da atividade do Estado como viabilizadora da estrutura pública capaz de pôr em prática e viabilizar o cumprimento das regras que redundam na proteção do homem - o que acontece frequentemente -, estaremos diante de um fenômeno jurídico com lugar no chamado direito público. Se, por outro lado, o ponto de análise é a gerência de aspectos que viabilizem o exercício de fato e de direito, da humanidade da pessoa, é possível que haja necessidade de se enfrentar o problema a partir de princípios de direito privado. $^{40}$

Por conseguinte, entendemos que a distinção entre direito público e direito privado ainda é relevante para a ciência jurídica, mesmo porque a sociedade do início do século XXI não abdicou da proteção de sua esfera privada em favor da coletividade. Contudo, o fato de tal diferenciação ter se tornado mais complexa não significa que tenha deixado de existir, mas que tornou mais exigente o trabalho dos operadores do direito.

\section{A SITUAÇÃO DOS DIREITOS DA PERSONALIDADE}

Abandonada a cizânia acerca da polarização público-privado do direito, impende analisar, neste momento, a posição ocupada pelos direitos da personalidade, ora concebidos na categoria de interesses privados, ora categorizados no rol dos interesses públicos ou de interesses híbridos, a depender dos ventos doutrinários.

A partir de 1945 os direitos da personalidade se difundiram e se positivaram, sem perder a ligação umbilical com os direitos fundamentais, mesmo porque muitos deles estão, historicamente, entre os mais antigos e importantes direitos fundamentais ${ }^{41}$.

A aproximação fica ainda mais evidente se observarmos que os direitos da personalidade se desenvolveram paralelamente ao movimento de constitucionalização do direito civil, daí surgindo o problema de se saber se ao direito civil interessam os conteúdos normativos constitucionalizados ou se tais situações são agora abarcadas pela teoria juspublicista.

Em paralelo, ganha relevância a doutrina da eficácia "privada" ou "horizontal" dos direitos, liberdades e garantias (Drittwirkung) ${ }^{42}$, a ensanchar a couraça constitucional protetiva

\footnotetext{
${ }^{39}$ NERY, Rosa Maria de Andrade, Introdução ao pensamento jurídico e à teoria geral do Direito Privado, p. 173.

${ }^{40}$ NERY, Rosa Maria de Andrade, Introdução ao pensamento jurídico e à teoria geral do Direito Privado, p. 174.

${ }^{41}$ MELLO, Cláudio Ari. Contribuição para uma teoria híbrida dos direitos de personalidade. In: SARLET, Ingo Wolfgang (org.). O novo Código Civil e a Constituição. Porto Alegre: Livraria do Advogado, 2003, p. 77.

${ }^{4}$ Conforme esclarece Gerhard Robbers, na Alemanha os direitos fundamentais vinculam de forma imediata o Poder Legislativo, o Poder Executivo e o Poder Judiciário (art. 1, 3 da Lei Fundamental), no entanto, no que toca aos particulares, a vinculação imediata dos direitos fundamentais é reconhecida somente no que toca ao art. 9, 3 da Lei Fundamental, que cuida da liberdade de associação (Koalitionsfreiheit). Assim, reconhecem os juristas alemães a teoria da vigência mediata dos direitos fundamentais (Theorie der mittelbaren Drittwirkung) sobre todos os ramos do direito, inclusive sobre o direito privado (ROBBERS, Gerhard, Einführung in das deutsche Recht, p. 50). Nesse mesmo sentido se manifestou o BVerfG no caso Lüth. O Tribunal Federal suíço, esclarece Claus-Wilhelm Canaris, também asseverou que "pelo menos a eficácia indirecta em relação a terceiros, no sentido de um imperativo de interpretação das normas de direito privado em conformidade com os direitos fundamentais, é praticamente
} Revista de Direito Brasileira | São Paulo, SP | v. 19 | n. 8 | p. 208 - 220 |Jan./Abr. 2018 
dos indivíduos não apenas em face das afrontas do poder estatal, mas nas relações jurídicas privadas, "na investidura dos particulares, a título principal, como sujeitos passivos dos direitos subjetivos fundamentais" $"$. Trata-se de problema que exaspera a tarefa de alocar os direitos da personalidade no arco do direito privado. ${ }^{44}$

Esses dados conduziram muitos doutrinadores a admitir que a teoria geral dos direitos da personalidade deve "envolver uma confluência e um hibridismo de institutos de direito constitucional e de direito civil". ${ }^{45}$

De fato, a confluência entre o papel do Estado na sociedade contemporânea e a expressa previsão dos direitos da personalidade na Constituição e no Código Civil parece desenhar a ágora ideal para a defesa do caráter dúplice ou híbrido desses direitos.

Não é outro o entendimento de Cláudio Ari Mello, que afirma que os direitos da personalidade são "[...] um lócus de encontro entre as duas esferas do universo jurídico", o que lhes dá uma natureza híbrida. ${ }^{46}$

Todavia, se consideramos os direitos da personalidade, pelo fato deles terem sido constitucionalizados, como uma categoria híbrida, o mesmo raciocínio deverá ser seguido com todos os demais direitos previstos na Constituição, como é o caso do direito de propriedade (art. $5^{\circ}, \mathrm{XXII}$ ), do direito de herança (art. 5, $\mathrm{XXX}$ ), do direito de família (arts. 226 e ss), dos direitos sociais (art. $7^{\circ}$ ) etc.

Nesta linha, o caráter analítico da Constituição da República conduziria, praticamente, à extinção do direito privado e ao reconhecimento de que no Brasil só existem direitos híbridos e direitos públicos, o que não é exagero, eis que os brasileiros têm uma verdadeira obsessão pela constitucionalização (basta lembrar, de passagem, que a nossa Carta Magna cuida até mesmo do Colégio Pedro II). ${ }^{47}$

Por outro lado, a aceitação da natureza mista ou mesmo pública dos direitos da personalidade pode recair na redução da regulamentação da vida do ser humano aos princípios do direito público, conduzindo justamente à despersonalização do homem, que passa a ser um autômato.

De fato, a maciça ingerência do direito público na esfera individual acaba por provocar a socialização da personalidade do ser humano, abstraindo sua identidade, o que em nada contribui para a realização da dignidade da pessoa humana ${ }^{48}$.

Não se pode colocar o direito a serviço de interferências desequilibradas, do Estado ou da sociedade, na vida das pessoas. Nesse campo, a atividade estatal deve se manter discreta,

reconhecida por todos", fazendo desse o seu entendimento (CANARIS, Claus-Wilhelm. Direitos fundamentais e direito privado. Trad. Ingo Wolfgang Sarlet e Paulo Mota Pinto. Coimbra: Almedina, 2009, p. 20-21). Há, entretanto, segundo Heinz Hübner, uma corrente de doutrinadores alemães, entre eles Nipperdey, que reconhecem a eficácia imediata (unmittelbare Wirkung) dos direitos fundamentais sobre todos os ramos do direito (HÜBNER, Heinz. Allgemeiner Teil des Bürgerlichen Gesetzbuches, p. 65). No mesmo sentido, Luiz Edson Fachin assevera que a aplicabilidade da norma constitucional se dá de forma direta e imediata sobre as relações privadas (FACHIN, Luiz Edson. Fundamentos, limites e transmissibilidade: anotações para uma leitura crítica, construtiva e de índole constitucional da disciplina dos direitos da personalidade no Código Civil brasileiro. In: CORRÊA, Elidia Aparecida de Andrade; GIACOIA, Gilberto; CONRADO, Marcelo (coord.). Biodireito e dignidade da pessoa humana. Curitiba: Juruá, 2007, p. 201).

${ }^{43}$ VIEIRA DE ANDRADE, José Carlos. Os direitos fundamentais na Constituição Portuguesa de 1976. 3. ed. Coimbra: Almedina, 2007, p. 262.

${ }_{44}$ MELLO, Cláudio Ari. Contribuição para uma teoria híbrida dos direitos de personalidade. In: SARLET, Ingo Wolfgang (org.). O novo Código Civil e a Constituição. Porto Alegre: Livraria do Advogado, 2003, p. 80.

${ }^{45}$ MELLO, Cláudio Ari. Contribuição para uma teoria híbrida dos direitos de personalidade. In: SARLET, Ingo Wolfgang (org.). O novo Código Civil e a Constituição. Porto Alegre: Livraria do Advogado, 2003, p. 83.

${ }^{46}$ MELLO, Cláudio Ari. Contribuição para uma teoria híbrida dos direitos de personalidade. In: SARLET, Ingo Wolfgang (org.). O novo Código Civil e a Constituição. Porto Alegre: Livraria do Advogado, 2003, p. 81.

${ }^{47}$ Cf. art. 242, $\$ 2^{\circ}$ do ADCT.

${ }^{48}$ BORGES, Roxana Cardoso Brasileiro. Dos Direitos da Personalidade. In: LOTUFO, Renan; NANNI, Giovanni Ettore (coord.). Teoria Geral do Direito Civil. São Paulo: Atlas, 2008, p. 257.

Revista de Direito Brasileira | São Paulo, SP | v. 19 | n. 8 | p. 208 - 220 |Jan./Abr. 2018 
comedida, subordinada à realização da dignidade da pessoa humana, que não se coaduna com o arbítrio.

\section{CONCLUSÃO}

Concluindo, pode-se considerar que o Estado e a sociedade não têm o direito de se imiscuir na vida privada das pessoas e "impor aos particulares certos modos de vida íntima ou certas concepções de dignidade que apenas ao próprio indivíduo cabe eleger". " 49 isso fosse permitido, nossa sociedade não diferiria muito daquela nazifascista, onde a privacidade era sacrificada em nome de um suposto benefício coletivo.

Assim, o reconhecimento de um espaço "reservado à individualidade e às relações intersubjetivas, relativamente autônomo em face do Estado", continua a ser uma notável conquista da modernidade $^{50}$, que não pode ser ignorada em nome da coletividade.

Neste passo, Perlingieri e Femia defendem que não se sustenta, do ponto de vista constitucional, a consideração do interesse público como sendo aquele superior, visto que a autoridade do Estado está na legitimidade dos seus princípios, que não colimam uma relação de subordinação do cidadão, mas sim a realização dos interesses das pessoas ${ }^{51}$.

Há que se reconhecer, sem dúvida, a importância dos movimentos de reação ao liberalismo e ao neoliberalismo econômico. Todavia, não se pode adotar a mesma técnica quando se defronta a esfera privada das pessoas, distinta das atividades de conteúdo econômico e que em nada afetam direitos de terceiros ${ }^{52}$.

O processo de socialização das relações patrimoniais, capitaneado pelo direito constitucional, não deve ser trazido para o campo das relações extrapatrimoniais, pois nesse caso, ao invés de uma intromissão benéfica do Estado, estaremos diante de uma atuação bastante prejudicial, visto que não se pode simplesmente funcionalizar a pessoa humana e sua dignidade, subordinando seus direitos mais íntimos ao interesse público.

Daí admitir-se que na aplicação do direito existe um aspecto individualista e privatista, relevante para a pessoa humana, sendo exatamente neste núcleo que se aninham os direitos da personalidade $^{53}$.

Com isso, considerando que a vida, a integridade física, a honra, a liberdade, entre outros bens, "satisfazem aspirações e necessidades próprias do indivíduo considerado em si mesmo", pontifica Adriano de Cupis que os direitos da personalidade fazem parte da esfera privada, pertencendo, por conseguinte, à categoria dos direitos privados 54 .

Nessa mesma linha, professa Rosa Maria de Andrade Nery:

[...] quer porque o direito privado se estrutura a partir do conceito de sujeito; quer porque o direito de humanidade tem por objeto as essências e as potências do ser humano; quer porque o corpo é uma das substâncias de nossa humanidade; quer porque o direito privado se interessa por toda a atividade que tenha relevância econômica, o chamado 'direito de personalidade' encontra aqui lugar para discussão e enfrentamento ${ }^{55}$.

\footnotetext{
${ }^{49}$ BORGES, Roxana Cardoso Brasileiro, Direitos de personalidade e autonomia privada, p. 99.

${ }^{50}$ MELLO, Cláudio Ari. Contribuição para uma teoria híbrida dos direitos de personalidade. In: SARLET, Ingo Wolfgang (org.). O novo Código Civil e a Constituição. Porto Alegre: Livraria do Advogado, 2003, p. 82.

${ }^{51}$ PERLINGIERI, Pietro; FEMIA, Pasquale, Nozioni introduttive e principi fondamentali del diritto civile, p. 70-71.

${ }^{52}$ BORGES, Roxana Cardoso Brasileiro, Direitos de personalidade e autonomia privada, p. 98.

${ }^{53}$ BORGES, Roxana Cardoso Brasileiro. Dos Direitos da Personalidade. In: LOTUFO, Renan; NANNI, Giovanni Ettore (coord.). Teoria Geral do Direito Civil. São Paulo: Atlas, 2008, p. 257.

${ }_{55}^{54}$ CUPIS, Adriano de. Os direitos da personalidade, p. 34.

${ }^{55}$ NERY, Rosa Maria de Andrade, Introdução ao pensamento jurídico e à teoria geral do Direito Privado, p. 285.
} Revista de Direito Brasileira | São Paulo, SP | v. 19 | n. 8 | p. 208 - 220 |Jan./Abr. 2018 
Enéas Costa Garcia também vê como sendo de direito privado esse regime jurídico, ainda que seu fundamento último, "tal como ocorre com os direitos fundamentais, possa ser fixado na Constituição". 56

Renan Lotufo entende que não há como deixar de enquadrar esses direitos "na categoria dos direitos privados, pois eles satisfazem aspirações e necessidades próprias do indivíduo".57

Alinhamo-nos a esses autores, entendendo que não obstante a admissão de algumas interferências do direito público no campo dos direitos da personalidade, tal atuação deve ser bastante limitada, visando tão somente ao atendimento da dignidade da pessoa humana, o que, por si só, não tem o condão de afastar do direito civil a tutela dos direitos da personalidade, mesmo porque o direito privado sempre conviveu com normas cogentes, inarredável pela vontade das partes.

Contudo, quando passamos do âmbito dos direitos da personalidade para o patamar constitucional da tutela da dignidade humana, devemos ter em conta que a proteção deve se dar de forma integrada, o que certamente deixa de lado a dicotomia direito público e direito privado, situando-se, na verdade, acima dela ${ }^{58}$, pois a dignidade da pessoa humana é o valor fonte do nosso ordenamento jurídico.

E parece que não há muita divergência no que toca à colocação da tutela da dignidade da pessoa humana acima das telas que separam a seara pública e a privada, dado que, em última instância, a pessoa humana demanda tutela unitária. A despeito disso, a distinção entre direitos fundamentais e direitos da personalidade não deixa de ser assaz importante, tendo em vista o seu papel facilitador do trabalho do operador do direito. Nesta esteira, destaca-se o escólio de Gustavo Tepedino, a esclarecer que a proteção constitucional da dignidade pessoa humana "supera a setorização da tutela jurídica (a partir da distinção entre os direitos humanos, no âmbito do direito público, e os direitos da personalidade, na órbita do direito privado) bem como a tipificação de situações previamente estipuladas, nas quais pudesse incidir o ordenamento". 59

E não poderia ser diferente, já que a tutela constitucional da pessoa humana, de acordo com Perlingieri e Femia, funda a legitimidade do ordenamento jurídico e a soberania do próprio Estado $^{60}$.

Pode-se concluir que se seguirmos uma visão parcial da tutela da pessoa humana (certamente interessante do ponto de vista prático e didático), os direitos da personalidade aparecem, sobretudo, como direitos privados, enquanto que os direitos fundamentais se aquartelam no âmbito do direito público. Porém, quando uma visão unitária da pessoa humana for imprescindível para a solução do problema posto, então é manifesta a superação da setorização, já que a dignidade da pessoa humana é a pedra angular do sistema jurídico e não só da seara pública ou privada.

\section{REFERÊNCIAS BIBLIOGRAFICAS}

AZEVEDO, Álvaro Villaça; NICOLAU, Gustavo Rene. Código civil comentado: das pessoas e dos bens: artigos $1^{\circ}$ a 103. AZEVEDO, Álvaro Villaça (coord.). São Paulo: Atlas, 2007, v. I.

BROX, Hans; WALKER, Wolf-Dietrich, Allgemeiner Teil des BGB, 36 ed. München: Vahlem,2016.

\footnotetext{
${ }^{56}$ GARCIA, Enéas Costa, Direito geral da personalidade no sistema jurídico brasileiro, p. 144.

${ }^{57}$ LOTUFO, Renan, Código Civil comentado: parte geral (arts. $1^{\circ}$ a 232), p. 53.

58 TEPEDINO, Gustavo, Temas de direito civil, p. 57.

${ }^{59}$ TEPEDINO, Gustavo. Introdução: Crise de fontes normativas e técnica legislativa na parte geral do Código Civil de 2002. In: TEPEDINO, Gustavo (coord.). A parte geral do novo Código Civil: Estudos na perspectiva civilconstitucional. 3. ed. Rio de Janeiro: Renovar, 2007, p. XXIV.

${ }^{60}$ PERLINGIERI, Pietro; FEMIA, Pasquale, Nozioni introduttive e principi fondamentali del diritto civile, p. 72. Revista de Direito Brasileira | São Paulo, SP | v. 19 | n. 8 | p. 208 - 220 |Jan./Abr. 2018
} 
CORRÊA, Elidia Aparecida de Andrade; GIACOIA, Gilberto; CONRADO, Marcelo (coord.). Biodireito e dignidade da pessoa humana. Curitiba: Juruá, 2007.

CUPIS, Adriano de. Os direitos da personalidade. São Paulo: Romana Jurídica, 2004.

DINIZ, Maria Helena. Compêndio de Introdução à Ciência do Direito. 19. ed. São Paulo: Saraiva, 2008.

DONEDA, Danilo. Os direitos da personalidade no novo Código Civil. In: TEPEDINO, Gustavo (org.). A parte geral do novo Código Civil. 3. ed. Rio de Janeiro: Renovar, 2007.

FERRAZ JUNIOR, Tercio Sampaio. Introdução ao estudo de direito: técnica, decisão, dominação. 2. ed. São Paulo: Atlas, 1994.

GARCIA, Enéas Costa, Direito geral da personalidade no sistema jurídico brasileiro. São Paulo, SP: Juarez de Oliveira, 2007.

LOTUFO, Renan; NANNI, Giovanni Ettore (coord.). Teoria Geral do Direito Civil. São Paulo: Atlas, 2008.

LOTUFO, Renan; NANNI, Giovanni Ettore (coord.). Teoria Geral do Direito Civil. São Paulo: Atlas, 2008.

MARTINS-COSTA, Judith. A reconstrução do direito privado: reflexos dos princípios, diretrizes e direitos fundamentais constitucionais no direito privado. São Paulo: Revista dos Tribunais, 2002.

NERY, Rosa Maria de Andrade, Introdução ao pensamento jurídico e à teoria geral do Direito Privado.

PERLINGIERI, Pietro; FEMIA, Pasquale. Nozioni introduttive e principi fondamentali del diritto civile. Napoli: Edizioni Scientifiche Italiane, 2004.

SARLET, Ingo Wolfgang (org.). O novo Código Civil e a Constituição. Porto Alegre: Livraria do Advogado, 2003.

TEPEDINO, Gustavo (coord.). A parte geral do novo Código Civil: Estudos na perspectiva civilconstitucional. 3. ed. Rio de Janeiro: Renovar, 2007.

VIEIRA DE ANDRADE, José Carlos. Os direitos fundamentais na Constituição Portuguesa de 1976. 3. ed. Coimbra: Almedina, 2007.

ZANINI, Leonardo Estevam de Assis. Direito de autor. São Paulo: Saraiva, 2015. . Direitos da personalidade. São Paulo: Saraiva, 2011. 